\title{
Surviving Sepsis Campaign: Guidelines on the Management of Critically Ill Adults with Coronavirus Disease 2019 (COVID-19)
}

R.K.Kamel, M.A.khashaba and H.M.Soliman

Anesthesiology and Intensive Care Dept.,Faculty of Medicine, Benha Univ., Benha, Egypt

E-Mail:hend@gmail.com

\begin{abstract}
Human contamination by the novel viral microbe SARS-CoV-2 outcomes in a clinical condition named Coronavirus Disease 2019 (COVID-19). Albeit most of COVID-19 cases are self-restricting, a considerable minority of patients create sickness adequately extreme to require serious consideration. Highlights of basic ailment related with COVID-19 incorporate hypoxemic respiratory disappointment, intense respiratory misery disorder (ARDS), stun, and different organ brokenness conditions (MODS).As Covid sickness 2019 (COVID-19) spreads across the world, the emergency unit local area should get ready for the difficulties related with this pandemic. Smoothing out of work processes for quick analysis and detachment, clinical administration, and contamination avoidance will not be important just to patients with COVID19 , yet additionally to medical care laborers and different patients who are in danger from nosocomial transmission. The board of intense respiratory disappointment and haemodynamics is key ICU experts, emergency clinic overseers, governments, and strategy producers should plan for a considerable expansion in basic consideration bed limit, with an attention on framework and supplies, yet in addition on staff the executives. Basic consideration emergency to permit the apportioning of scant ICU assets may be needed.ICU specialists, clinic heads, governments, and strategy creators should get ready for a significant expansion in basic consideration bed limit, with an attention on foundation and supplies, yet in addition on staff the executives.
\end{abstract}

Keywords: Coronavirus, Sepsis Campaign, pandemics.

\section{Introduction}

Toward the finish of 2019, a novel Covid, named extreme intense respiratory disorder Covid 2 (SARSCoV-2) brought about an intense respiratory ailment pestilence in Wuhan, China [1]. The World Health Organization (WHO) named this ailment Coronavirus Disease 2019 (COVID-19).

When this rule board was amassed, the COVID-19 had gotten a pandemic and had influenced more than 120,000 people in excess of 80 nations, and brought about in excess of 5000 passings around the world [2].

The WHO and the United States Center for Disease Control and Prevention (CDC) have given fundamental direction on contamination control, screening and analysis in everybody, except there is restricted direction on the intense administration of basically sick patients with extreme sickness because of COVID-19 [3].

\section{Infection control}

A new report from the Chinese Center of Disease Control and Prevention portrayed 72,314 instances of COVID-19 from China, of which 44,672 were lab affirmed. Among lab affirmed cases, 1,716 (3.8\%) were medical care laborers, the greater part of whom, 63\% (1080 of 1716), obtained the disease in Wuhan. The report portrays that $14.8 \%$ (247 of 1668) of tainted medical care laborers had extreme or basic disease, and that 5 kicked the bucket [4].

For medical services laborers performing airborne creating procedures* on patients with COVID-19 in the ICU, we suggest utilizing fitted respirator veils (N95 respirators, FFP2, or same), instead of careful/clinical covers, notwithstanding other individual defensive hardware (i.e., gloves, outfit, and eye insurance, for example, a face shield or wellbeing goggles) [4].
Respirator veils are intended to hinder 95 - 99\% of vaporized particles. The N95 type adjusts to United States Federal Drug Agency guidelines, and the FFP2 adjusts to European norms - European Committee for Standards principles). Staff ought to be fit tried for each unique sort. Careful (otherwise called clinical veils) are intended to impede enormous particles, drops and splashes, yet are less successful in hindering little molecule pressurized canned products $(<5$ micrometers) [5].

We suggest performing vaporized creating strategies on ICU patients with COVID-19 of every a negative pressing factor room as Negative pressing factor rooms are a designing control expected to forestall the spread of infectious airborne microbes from one space to another (for example measles, and tuberculosis). The fundamental objective is to dodge the unintentional arrival of microbes into a bigger space and open office, consequently securing medical services laborers and patients in an emergency clinic setting [6].

Negative pressing factor rooms have demonstrated to be a successful measure that assisted with keeping away from cross-tainting during the SARS pestilence. As needs be, for airborne producing methods, the WHO direction on COVID-19 suggests the utilization of negative pressing factor rooms with at least 12 air changes each hour or possibly $160 \mathrm{~L} /$ second/patient in offices with regular ventilation [3].

Bronchoscopies are among the systems at most elevated danger of aerosolization, and their utilization ought to be limited. Non-obtrusive ventilation is likewise at high danger of aerosolization, and procedures have been portrayed to contain the danger of infection spread, additionally as per a past report on SARS disease [7]. 
For COVID-19 patients requiring endotracheal intubation, we suggest that endotracheal intubation be performed by the medical services laborer who is generally knowledgeable about aviation route the executives to limit the quantity of endeavors and danger of transmission [8].

\subsection{Laboratory diagnosis and specimens}

The WHO as of late proclaimed a COVID-19 pandemic. Appropriately, every basically sick patient showing up with proof of respiratory disease ought to be considered possibly tainted with SARS-CoV-2. Constant polymerase chain response (RT-PCR) is the best quality level for comparative viral diseases, including SARS [2].

Quite, COVID-19 represents a few symptomatic difficulties because of an all-encompassing hatching period (around fourteen days) that incorporates a drawn out stretch (roughly 5 days) of viral shedding preceding the beginning of manifestations. In addition, the span of asymptomatic shedding isn't just factor yet may likewise contrast dependent on the anatomic level (upper versus lower) of the disease in the respiratory framework .Accordingly; the presentation of biomolecular measure may differ by site of testing [9].

Coronavirus determination depends on RT-PCR testing of respiratory examples from nasopharyngeal and oropharyngeal swabs, and of lower respiratory lot tests at whatever point conceivable. Bronchoalveolar lavage ought to be restricted and performed just whenever demonstrated and with sufficient safeguards, because of the danger of aerosolization and resulting openness of medical care experts.

Likewise, sputum enlistment ought to be maintained a strategic distance from because of expanded danger of aerosolization. Tracheal suction examples seem to convey a lower danger of aerosolization and can some of the time be gotten without disengaging the patient from the ventilator [10].

\subsection{Supportive Care}

Hemodynamic Support: The detailed pervasiveness of stun in grown-up patients with COVID-19 is profoundly factor (from $1 \%$ to $35 \%$ ), contingent upon the patient populace contemplated, the seriousness of sickness, and the meaning of stun. In a new report summing up the epidemiological qualities of 44,415 Chinese patients with COVID-19, 2087 (5\%) were analyzed as basic cases, characterized as extreme hypoxemia and additionally the presence of other organ disappointment, including stun [4].

Heart injury (height of cardiovascular injury biomarkers over the 99th percentile upper reference limit) has been accounted for in $7 \%$ to $23 \%$ of patients with COVID-19 in Wuhan, China. While the predominance of cardiovascular injury may correspond with the pervasiveness of stun, an absence of precise evaluating for heart brokenness in hemodynamically stable patients implies that this affiliation can't be taken as certain $[11,12]$.
Liquid treatment: In grown-ups with COVID-19 and stun, we recommend utilizing dynamic boundaries skin temperature, slim topping off time, as well as serum lactate estimation over static boundaries to evaluate liquid responsiveness

In a precise survey and meta-examination of 13 RCTs analyzing the impact of dynamic evaluation of liquid treatment on significant patient results in grownup ICU patients requiring liquid revival [13], the utilization of dynamic appraisal to direct liquid treatment was found to diminish mortality, ICU length of stay and span of mechanical ventilation. Of note, just 1 preliminary zeroed in on patients with septic stun.

Dynamic boundaries utilized in these preliminaries included stroke volume variety (SVV), beat pressure variety (PPV), and stroke volume change with uninvolved leg raising or liquid test. Among the inspected dynamic boundaries, latent leg rising followed by PPV and SVV seems to foresee liquid responsiveness with most noteworthy exactness [14]. The static boundaries included segments of early goaldirected treatment, for example focal venous pressing factor (CVP) and mean blood vessel pressure (MAP)

For the intense revival of grown-ups with COVID19 and stun, we suggest utilizing crystalloids over colloids. Since there exists no immediate proof on stun in patients with COVID-19, the board put together this proposal with respect to backhanded proof from basically sick patients all in all.

\subsection{Ventilatory Support}

The pervasiveness of hypoxic respiratory disappointment in patients with COVID-19 is $19 \%$. Ongoing reports from China showed that $4 \%$ to $13 \%$ of COVID-19 patients in these investigations got nonobtrusive positive pressing factor ventilation (NIPPV), and that $2.3 \%$ to $12 \%$ required intrusive mechanical ventilation [15].

In grown-ups with COVID-19, we propose beginning supplemental oxygen if the fringe oxygen immersion (SPO2) is $<92 \%$ (powerless suggestion, bad quality proof), and suggest beginning supplemental oxygen if SPO2 is $<90 \%$

In grown-ups with COVID-19 and intense hypoxemic respiratory disappointment on oxygen, we suggest that SPO2 be kept up no higher than 96\% [1].

A new report depicted the infection course of 1,009 patients with COVID-19 in China and showed that $41 \%$ of all hospitalized patients and more than $70 \%$ of those with serious illness required supplemental oxygen. In basically sick patients, hypoxia can be hindering and is related with helpless results [16].

In precisely ventilated grown-ups with COVID-19 and ARDS, we suggest utilizing low flowing volume (Vt) ventilation ( $\mathrm{Vt} 4-8 \mathrm{~mL} / \mathrm{kg}$ of anticipated body weight), over higher flowing volumes $(\mathrm{Vt}>8 \mathrm{~mL} / \mathrm{kg})$ [16].

As of now there are no investigations tending to mechanical ventilation procedures in COVID-19 
patients. Notwithstanding, the board of specialists accepts that precisely ventilated patients with COVID19 ought to be overseen correspondingly to different patients with intense respiratory disappointment in the ICU [16].

While mechanical ventilation is a conceivably lifesaving mediation, it can demolish lung injury and, through ventilator-initiated lung injury (VILI), add to multiorgan disappointment in patients with ARDS [17]. One of the fundamental ventilator techniques to limit VILI is low Vt ventilation.

\subsection{COVID-19 therapy}

Cytokine storm condition is a hyperinflammatory express that is portrayed by fulminant multi-organ disappointment and height of cytokine levels. A new report from China showed that COVID-19 is related with a cytokine height profile that is suggestive of auxiliary hemophagocytic lymphohistiocytosis (HLH) [18].

A few creators even propose that we screen basically sick COVID-19 patients for optional HLH utilizing the Hscore (19), and that corticosteroids and other immunosuppressive specialists can be utilized in patients with a high probability of HLH.

There are no controlled clinical preliminaries on the utilization of corticosteroids in COVID-19 patients or other Covids. A distributed, yet not friend assessed, report of 26 patients with serious COVID-19 reports that the utilization of methylprednisolone at 1$2 \mathrm{mg} / \mathrm{kg} / \mathrm{day}$ for 5 to 7 days was related with more limited span of supplemental oxygen use (8.2 days versus 13.5 days; $\mathrm{P}<0.001)$ and improved radiographic discoveries [15]

The impact of corticosteroids in COVID-19 patients with sepsis or septic stun might be unique. Ongoing deliberate surveys and meta-investigations of RCTs in sepsis showed little enhancements in mortality and quicker goal of stun with corticosteroid use, contrasted and not utilizing corticosteroids [20].

In patients with COVID-19 and hypoxic respiratory disappointment requiring mechanical ventilation, the board propose empiric antimicrobial treatment, on the premise that superinfection is sensibly normal in this populace and may to prompt a generous expansion in mortality, as in pandemic flu [21].

Along these lines, basically sick patients with suspected or affirmed COVID-19 ought to be treated with empiric antimicrobial treatment as per the clinical condition (e.g., local area procured or hospitalacquired pneumonia). Optional diseases happen in patients with COVID-19, however the frequency is obscure given the exceptionally restricted information [22]. These diseases ought to be treated by clinical and microbiological information.

The utilization of non-steroidal mitigating medications to treat fever in patients with COVID-19 keeps on being discussed. Until more proof is accessible, we propose utilizing acetaminophen/paracetamol to treat fever. Given the security of acetaminophen and absence of mischief in the collection of proof, expanding patient solace through fever the board possibly significant

Chloroquine and its metabolite, hydroxychloroquine, are antimalarial specialists that have shown antiviral impacts on SARS-CoV and SARS-CoV-2 in vitro [23]. Earlier examinations discovered inhibitory impacts of chloroquine for various RNA infections in vitro, yet RCTs in treatment of dengue and chikungunya infection diseases and of flu prophylaxis neglected to exhibit antiviral or clinical advantages [24].

Since chloroquine isn't accessible in certain nations, hydroxychloroquine is another option. A new report in China investigated different dosing regimens of chloroquine and hydroxychloroquine utilizing physiologically-based pharmacokinetic models [25]. The examination discovered hydroxychloroquine to be more intense than chloroquine in hindering SARS-CoV2 in vitro

A new orderly survey found no distributed examinations in COVID-19 patients [26] Forthcoming the consequences of progressing preliminaries, we couldn't give a proposal possibly in support of chloroquine.

Remdesivir is the prodrug of an adenosine simple, which consolidates into incipient viral RNA chains and results in untimely end. It was viewed as the most encouraging medication in a casual discussion on research prioritization of up-and-comer helpful specialists by WHO [3]. As of now, there are distributed case reports yet no distributed preliminaries on the utilization of remdesivir in COVID-19. There are a few continuous RCTs that plan to look at the viability and wellbeing of intravenous remdesivir for serious COVID-19

There is lacking proof to give a proposal on the utilization of different medications and mixtures like intravenous immunoglobulins, gaining strength plasma, antiviral specialists, and recombinant rIFNs to be utilized in treatment of COV-19 patients.

\section{Conclusion}

ICU specialists, clinic executives, governments, and strategy producers should get ready for a significant expansion in basic consideration bed limit, with an emphasis on framework and supplies, yet additionally on staff the board. Basic consideration emergency to permit the proportioning of scant ICU assets may be required. Analysts should address unanswered inquiries, including the part of repurposed and test treatments. Joint effort at the neighborhood, local, public, and global level offers the most obvious opportunity with regards to endurance for the basically sick.

\section{References}

[1] WJ.Guan, ZY.Ni, Y.Hu, WH. Liang, CQ.Ou, JX.He, L.Liu, H.Shan, CL.Lei, DSC.Hui, B .Du, LJ.Li, G.Zeng, KY. Yuen, RC. Chen, CL.Tang, T.Wang, PY.Chen, J.Xiang, SY.Li, JL.Wang, ZJ.Liang, YX.Peng, L.Wei, Y.Liu, YH. Hu, 
P.Peng, JM.Wang, JY.Liu, Z. Chen, G.Li, ZJ.Zheng, SQ.Qiu, J.Luo, CJ.Ye, SY.Zhu, NS.Zhong, C.China Medical Treatment Expert Group for. Clinical Characteristics of Coronavirus Disease 2019 in China. N Engl J Med, Vol.7, PP.77-999,2020.

[2] European Centre for Disease Prevention and Control. Situation update worldwide, 4 March 2020. In: Editor (ed)^(eds) Book Situation update worldwide, 4 March. City, Vol.8, PP.55-100,2020

[3] World Health Organization. Clinical management of severe acute respiratory infection (sari) when covid-19 disease is suspected. In: Editor $(\text { ed })^{\wedge}($ eds) Book Clinical management of severe acute respiratory infection (sari) when covid-19 disease is suspected. City, Vol.7, PP.12-77,2020.

[4] Z.Wu,J.M.McGoogan. Characteristics of and Important Lessons From the Coronavirus Disease 2019 (COVID-19) Outbreak in China: Summary of a Report of 72314 Cases From the Chinese Center for Disease Control and Prevention. JAMA, Vol.88, PP.77-199,2020.

[5] D.K.Milton,M.P.Fabian, B.J.Cowling, M.L.Grantham, J.J.McDevitt. Influenza virus aerosols in human exhaled breath: particle size, culturability, and effect of surgical masks. PLoS Pathog, Vol. 9, PP.e1003205,2013.

[6] SJ.Twu, TJ.Chen, CJ.Chen, SJ.Olsen, LT.Lee, T.Fisk, KH.Hsu, SC.Chang, KT.Chen, IH .Chiang, YC.Wu, JS.Wu, SF.Dowell. Control measures for severe acute respiratory syndrome (SARS) in Taiwan. Emerg Infect Dis, Vol. 9, PP.718$720,2003$.

[7] L.Cabrini, G.Landoni, A.Zangrillo. Minimise nosocomial spread of 2019-nCoV when treating acute respiratory failure.Lancet, Vol.7, PP.395: 685,2020.

[8] LY. Yam, RC. Chen, NS. Zhong. SARS: ventilatory and intensive care. Respirology, Vol.8 Suppl, PP.S31-35,2003.

[9] NM.Linton, T.Kobayashi, Y.Yang, K.Hayashi, AR.Akhmetzhanov, SM.Jung, B.Yuan, R. Kinoshita, H.Nishiura. Incubation Period and Other Epidemiological Characteristics of 2019 Novel Coronavirus Infections with Right Truncation: A Statistical Analysis of Publicly Available Case Data. J Clin Med, Vol.9, PP.88119(2020)

[10] VM.Corman, O.Landt, M.Kaiser, R.Molenkamp, A.Meijer, DKW.Chu, T.Bleicker, S. Brunink, J.Schneider, ML.Schmidt, D.Mulders, BL.Haagmans, B.van der Veer, S.van den Brink, L.Wijsman, G.Goderski, JL.Romette, J.Ellis, M.Zambon, M.Peiris, H. Goossens, C.Reusken, MPG.Koopmans, C.Drosten. Detection of 2019 novel coronavirus (2019-nCoV) by real-time RTPCR. Euro Surveill, Vol.8, PP.22-99,2020.

[11]X.Yang, Y.Yu, J.Xu, H.Shu, J.Xia, H.Liu, Y.Wu, L.Zhang, Z.Yu, M.Fang, T.Yu, Y. Wang, S.Pan, X. Zou, S.Yuan, Y.Shang. Clinical course and outcomes of critically ill patients with SARSCoV-2 pneumonia in Wuhan, China: a singlecentered, retrospective, observational study. Lancet Respir Med, Vol.9, PP.88-125,2020.

[12]F.Zhou, T.Yu, R.Du, G.Fan, Y.Liu, Z.Liu, J.Xiang, Y.Wang, B.Song, X.Gu, L.Guan, Y. Wei, H.Li, X.Wu, J.Xu, S.Tu, Y.Zhang, H.Chen, B.Cao. Clinical course and risk factors for mortality of adult inpatients with COVID-19 in Wuhan, China: a retrospective cohort study. Lancet, Vol.3, PP.77-789,2020.

[13] J.M.Bednarczyk, J.A.Fridfinnson, A.Kumar, L.Blanchard, R.Rabbani, D.Bell, D.Funk, AF.Turgeon, AM.Abou-Setta, R.Zarychanski. Incorporating Dynamic Assessment of Fluid Responsiveness Into Goal-Directed Therapy: A Systematic Review and Meta-Analysis. Crit Care Med, Vol.45, PP.1538-1545,2017.

[14]P.Bentzer, DE.Griesdale, J.Boyd, K.MacLean, D.Sirounis, NT.Ayas. Will This Hemodynamically Unstable Patient Respond to a Bolus of Intravenous Fluids? JAMA, Vol.316, PP.1298$1309,2016$.

[15]D.Wang, B.Hu, C.Hu, F.Zhu, X.Liu, J.Zhang, B.Wang, H.Xiang, Z.Cheng, Y.Xiong, Y. Zhao, Y.Li, X.Wang, Z.Peng. Clinical Characteristics of 138 Hospitalized Patients With 2019 Novel Coronavirus-Infected Pneumonia in Wuhan, China. JAMA, Vol.9, PP.99-110, 2020

[16] W.Van den Boom, M.Hoy, J.Sankaran, M.Liu, H.Chahed, M.Feng, KC.See. The Search for Optimal Oxygen Saturation Targets in Critically Ill Patients: Observational Data From Large ICU Databases. Chest, Vol.157, PP.566-573,2020.

[17] AS.Slutsky, VM.Ranieri. Ventilator-induced lung injury. N Engl J Med, Vol. 369, PP.21262136,2013.

[18] C.Huang, Y.Wang, X.Li, L.Ren, J.Zhao, Y.Hu, L.Zhang, G.Fan, J.Xu, X.Gu, Z.Cheng, T.Yu, J.Xia, Y.Wei, W.Wu, X.Xie, W.Yin, H.Li, M.Liu, Y.Xiao, H.Gao, L.Guo, J.Xie, G. Wang, R.Jiang, Z.Gao, Q.Jin, J.Wang, B.Cao. Clinical features of patients infected with 2019 novel coronavirus in Wuhan, China. Lancet, Vol.395, PP.497506,2020.

[19] L.Fardet, L.Galicier, O.Lambotte, C.Marzac, C.Aumont, D.Chahwan, P.Coppo, G. Hejblum. Development and validation of the HScore, a score for the diagnosis of reactive hemophagocytic syndrome. Arthritis Rheumatol, Vol. 66, PP.26132620,2014.

[20] XJ.Lian, DZ.Huang, YS.Cao, YX.Wei, ZZ.Lian, TH.Qin, PC.He, YH.Liu, SH.Wang. Reevaluating the Role of Corticosteroids in Septic Shock: An Updated Meta-Analysis of Randomized Controlled Trials. Biomed Res Int, Vol.8, PP.3175047,2019.

[21] JA.McCullers. Do specific virus-bacteria pairings drive clinical outcomes of pneumonia? Clin Microbiol Infect, Vol. 19, PP. 113-118,2013. 
[22] J.Alfonso Rodriguez-Morales, A.Jaime. CardonaOspina, Estefanía Gutiérrez-Ocampo, Rhuvi Villamizar-Peña, Yeimer Holguin-Rivera, Juan Pablo Escalera-Antezana, Lucia Elena, Ranjit Sah, Clinical, laboratory and imaging features of COVID-19: A systematic review and metaanalysis, Travel Medicine and Infectious Disease, Vol.5,pp123-199, 2020.

[23]X.Yao, F.Ye, M.Zhang, C.Cui, B.Huang, P.Niu, X.Liu, L.Zhao, E.Dong, C.Song, S.Zhan, R.Lu, H.Li, W.Tan, D.Liu. In Vitro Antiviral Activity and Projection of Optimized Dosing Design of
Hydroxychloroquine for the Treatment of Severe Acute Respiratory Syndrome Coronavirus 2 (SARS-CoV-2). Clin Infect Dis.vol,.4, PP.44-156, 2020.

[24]F.Touret, X.de Lamballerie. Of chloroquine and COVID-19. Antiviral Res, Vol.9, PP.177: 104762,2020/

[25] A.Cortegiani, G. Ingoglia, M.Ippolito, A.Giarratano, S.Einav. A systematic review on the efficacy and safety of chloroquine for the treatment of COVID-19. J Crit Care, Vol.1, PP.33100,2020 . 